\title{
An Unusual Case of Extensively Drug Resistant Typhoid Fever
}

\author{
Jamil M. Bhatti ${ }^{1}$, Yousuf Memon ${ }^{2}$, Samreen Sarfaraz ${ }^{1}$, Naseem Salahuddin ${ }^{1}$ \\ 1. Infectious Diseases, The Indus Hospital, Karachi, PAK 2. Radiology, The Indus Hospital, Karachi, PAK
}

Corresponding author: Jamil M. Bhatti, muqtadir1692@gmail.com

\begin{abstract}
Enteric fever is a potentially fatal multisystemic illness caused primarily by Salmonella typhi and, to a lesser extent, by Paratyphi A, B, and C. Emergence of resistance has depleted the antimicrobial arsenal overtime, making treatment challenging and costly. In 2016, a new extensively drug resistant (XDR) strain of Salmonella typhi emerged in Sindh, which only responds to two antibiotics--carbapenems and azithromycin. Its clinical spectrum is not yet clear but increased morbidity and mortality is being observed with it. We present a severe case of XDR Salmonella typhi where the clinical course was complicated by delayed defervescence, severe hepatitis, soft tissue infection, and profuse lower gastrointestinal bleeding, which responded to a combination of carbapenem and azithromycin and an invasive procedure to contain bleeding from the cecal artery. The purpose of this case report is to highlight the morbidity, cost, and therapeutic challenges associated with severe XDR Salmonella typhi infection.
\end{abstract}

Categories: Infectious Disease

Keywords: xdr typhoid, salmonella typhi, hepatitis, disseminated intravascular coagulation, meropenem, azithromycin

\section{Introduction}

Enteric fever by $S$. typhi can result in severe disease with complications in 10\%-15\% of patients, including gastrointestinal bleeding, intestinal perforation, hepatitis, pancreatitis, typhoid encephalopathy, disseminated intravascular coagulation, hemolytic uremic syndrome, endocarditis, pneumonia, and, rarely, reactive hemophagocytic lymphohistiocytosis $(\mathrm{HLH})$ and rhabdomyolysis [1,2].

Received 02/02/2019 Review began 03/07/2019 Review ended 05/12/2019 Published 05/14/2019

\section{(c) Copyright 2019} Bhatti et al. This is an open access article distributed under the terms of the Creative Commons Attribution License CC-BY 3.0., which permits unrestricted use, distribution, and reproduction in any medium, provided the original author and source are credited.
Host factors associated with severe disease include infants, immunosuppression, female sex, and those infected with drug-resistant $S$. typhi [2]. Specific genetic polymorphisms in major histocompatibility complex class II and III genes have also been found in individuals with severe typhoid fever.

The bacterium grows intracellularly in the intestinal lymphoid tissue, presenting acutely with gastrointestinal symptoms and fever. The classic presentation is that of a prolonged fever, step-ladder in pattern, accompanied by malaise, abdominal pain, and constipation in the first two weeks, followed by diarrhea in the third week [3]. Metastatic infection in the liver, spleen, bone, and other viscera may occur. Many patients develop gastrointestinal bleeding and intestinal perforation.

Typhoid fever is a serious water-borne infection caused by Salmonella enterica that remains endemic in Pakistan due to contaminated water supplies and deplorable sanitary conditions. Over a 100,000 cases are reported annually. The emergence of drug-resistant strains has depleted the antimicrobial arsenal overtime, making treatment challenging and costly. In 2016, a new extensively drug resistant (XDR) strain resistant to five antibiotics emerged in Hyderabad and spread, infecting more than 8,000 people in 14 districts across Sindh up till now. Due to the acquisition of $\mathrm{H} 58$ haplotype mutation it does not respond to third generation cephalosporins. Carbapenems and azithromycin are antibiotics of last resort and further mutation threatens to make typhoid untreatable. Disturbing reports of azithromycin resistance are already emerging from South East Asia. The clinical spectrum of XDR Salmonella infection is unclear and it may increase the morbidity and mortality associated with typhoid.

\section{Case Presentation}

A 31-year-old woman was admitted with high grade intermittent fever, jaundice, and watery diarrhea of one month. A week into the febrile illness, she developed pain and inflammation over the right upper arm extending below the elbow. Her past history was relevant only for controlled hypothyroidism.

On examination, the patient was alert, oriented, but ill-appearing with fever, dehydration, and icterus. There was an inflamed, indurated swelling with blisters extending from the distal third of the upper arm to the proximal one-third of the forearm, involving the elbow joint. Movement at the joint was limited due to pain. The remainder of the examination was unremarkable except for mild tenderness over the epigastrium. Her laboratory investigations are shown in Table 1. 


\section{Cureus}

\begin{tabular}{|c|c|c|c|}
\hline Variables & Reference Range & On Admission & Peak Values \\
\hline Hemoglobin (g/dl) & 13.7-16.3 & 12.2 & \\
\hline PCV (Packed Cell Volume) & 41.9-48.7 & 39.5 & \\
\hline White Cell Count (per mm3) & $4,000-10,000$ & 9680 & \\
\hline \multicolumn{4}{|l|}{ Differential Count \% } \\
\hline Neutrophils & $40-70 \%$ & $51.1 \%$ & \\
\hline Lymphocytes & $20-45 \%$ & $38.8 \%$ & \\
\hline Monocytes & $02-10 \%$ & $7 \%$ & \\
\hline Eosinophils & $01-06 \%$ & $2.3 \%$ & \\
\hline Basophils & $00-01 \%$ & $0.8 \%$ & \\
\hline Platelets & $150-400^{\star} 109$ & 319 & \\
\hline Prothrombin Time (sec) & $11-16 \mathrm{sec}$ & $14 \mathrm{sec}$ & $21 \mathrm{sec}($ INR 1.85)* \\
\hline Creatinine (mg/dl) & $0.7-1.2$ & 0.65 & \\
\hline Potassium (mEq/L) & $3.5-5.0$ & 4.48 & \\
\hline Serum Albumin (g/dl) & $3.8-4.4$ & 3.06 & \\
\hline Total Bilirubin (mg/dl) & $0-1.4$ & $2.49^{\star}$ & $4.94^{\star}$ \\
\hline Direct Bilirubin (mg/dl) & $0-0.3$ & $2.02^{\star}$ & \\
\hline GGT (Gamma Glutamate Dehydrogenase) (U/L) & 08-61 & $425^{*}$ & \\
\hline ALT(Alanine Aminotransferase) (mg/dl) & $0-41$ & $123^{*}$ & \\
\hline Alkaline phosphatase (mg/dl) & $40-129$ & $211^{\star}$ & \\
\hline
\end{tabular}

\section{TABLE 1: Laboratory data}

*abnormal values

Viral hepatitis and human immunodeficiency virus (HIV) antibodies were negative. Two blood cultures grew Salmonella typhi that was resistant to ampicillin, chloramphenicol, co-trimoxazole, ciprofloxacin, ceftriaxone and cefixime, and sensitive to all carbapenems and azithromycin. An ultrasound (US) of the elbow revealed large fluid collection with septations, which was incised and drained. Salmonella typhi was isolated from culture of the pus with identical sensitivities as in the blood cultures.

Meropenem $1 \mathrm{gm} \mathrm{i} / \mathrm{v} 8$ hourly and azithromycin $500 \mathrm{mg}$ i/v od were started intravenously, but she continued to have high fever and the dose of meropenem was doubled on Day 5. During admission, the patient developed severe epigastric pain and vomiting for which she was kept nil per oral and a nasogastric tube was placed. She started to have small episodes of per rectal bleed from the eighth day of illness leading to an intermittent drop in hemoglobin. D-dimers were $>15000$ and fibrin degradation products $>20 \mathrm{ug} / \mathrm{ml}$ suggestive of disseminated intravascular coagulation (DIC), although the activated partial thromboplastin time (APTT) remained within normal limits. Supportive blood and blood products were continued. On the 11th day the patient started having massive per rectal bleed, became hypotensive and remained so despite aggressive blood transfusions. A computed tomography (CT) scan of the abdomen reported thickening at the ileocecal junction and cecal pole with significant mesenteric lymphadenopathy and fibrotic bands in both lung fields. Digital subtraction angiography was done to identify the source of gastrointestinal (GI) bleeding. Angiography of the superior mesenteric artery (SMA), inferior mesenteric artery (IMA), mesenteric arteries, and celiac artery was performed using a $5 \mathrm{~F}$ catheter and 035 hydrophilic guide wire. Non-ionic contrast was injected. Bleeding was detected from the cecal branch of the SMA, seen as a blush. Figure 1 shows blush of the contrast (arrow and circle) from the cecal artery, indicating acute bleeding in the cecum. 


\section{Cureus}

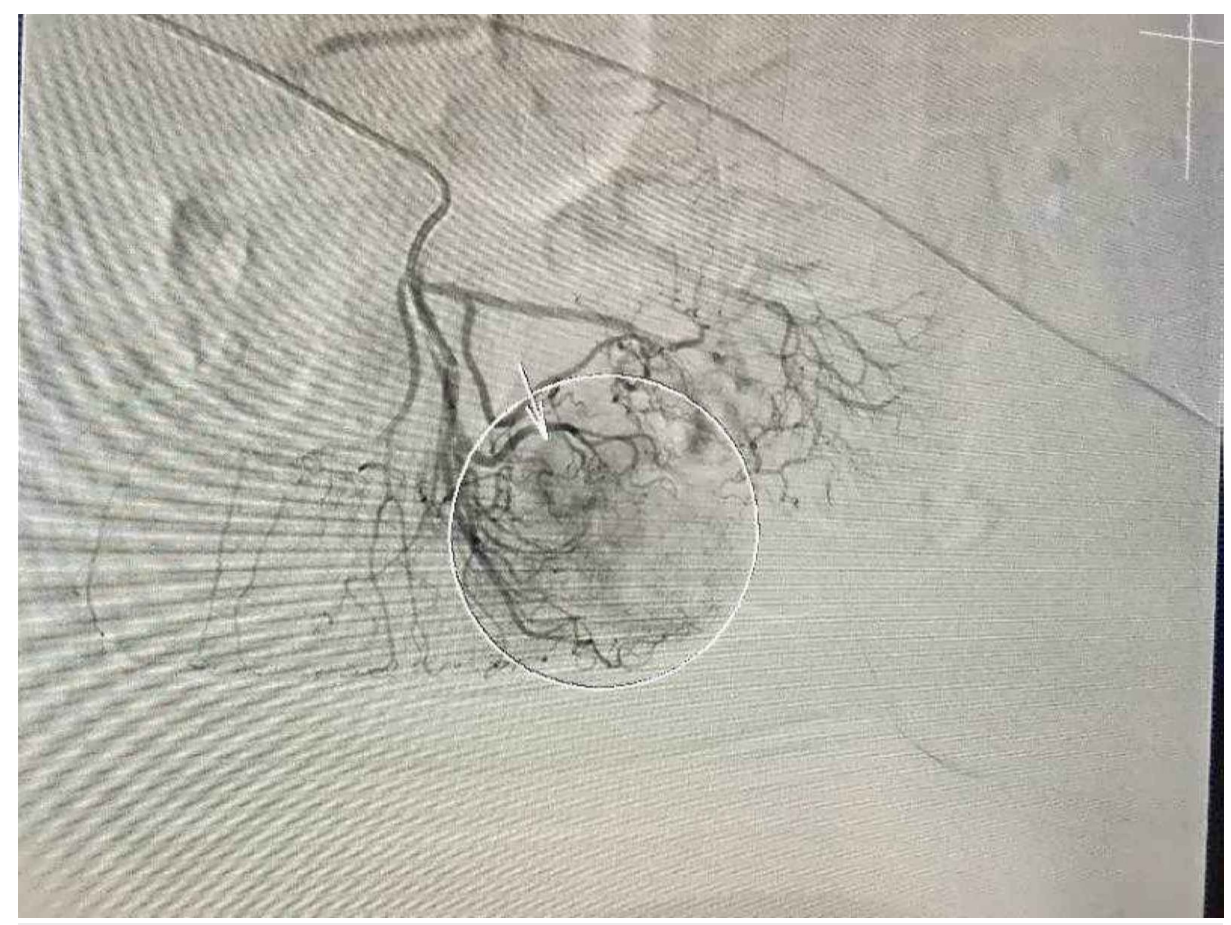

FIGURE 1: Image shows blush of the contrast (arrow and circle) from the cecal artery indicating acute bleeding in the cecum

The bleeding was stopped by using micro coils. The final angiogram showed cessation of bleeding (Figure 2).

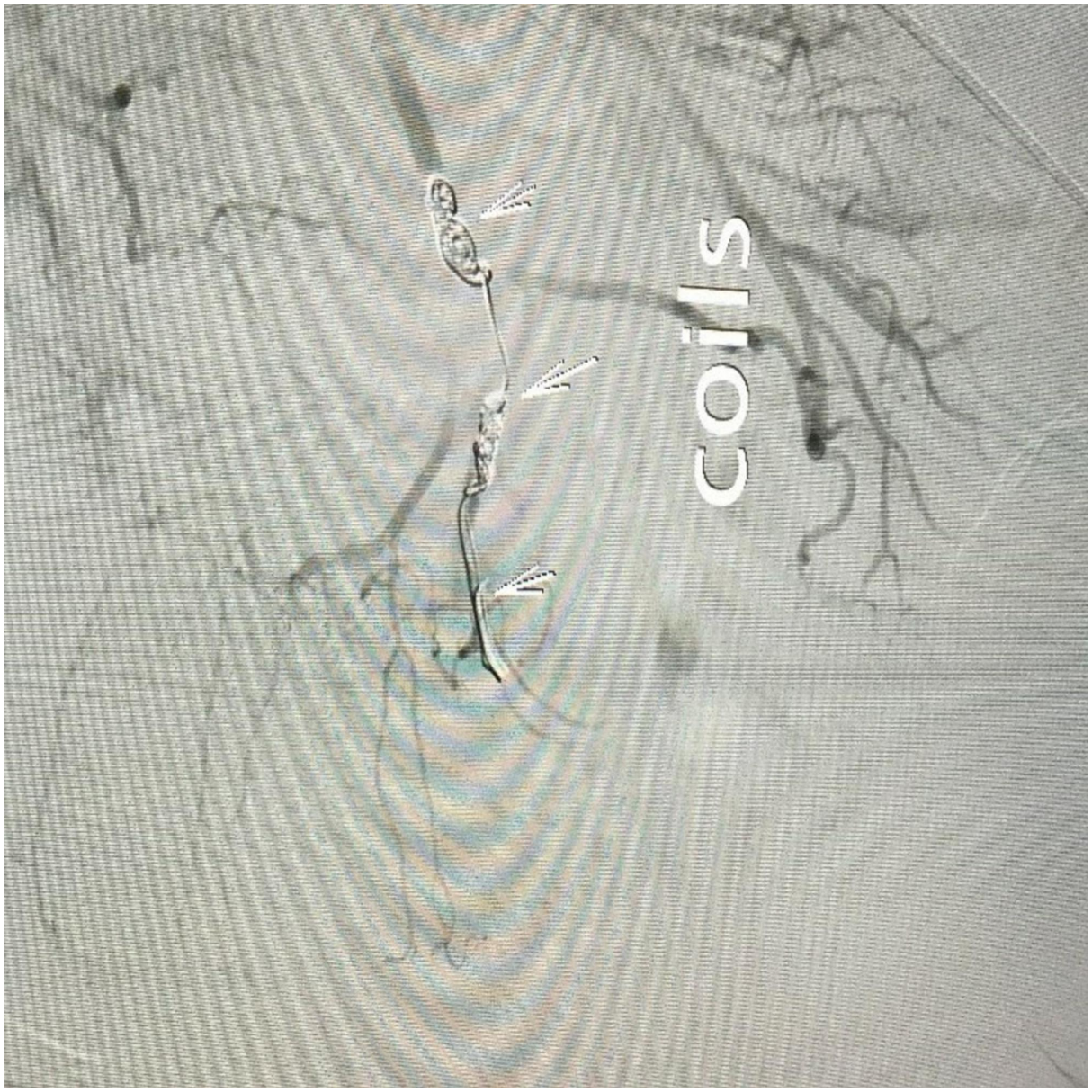

FIGURE 2: Post embolization by coils (arrows) and polyvinyl alcohol 
Defervescence occurred on Day 12. The patient subsequently improved clinically and her lab parameters returned to normal. She was discharged to home care on azithromycin $500 \mathrm{mg}$ daily for an additional one week. Follow-up as an outpatient an additional two weeks later showed complete recovery from the infection.

\section{Discussion}

Our patient had XDR S. typhi strain that was resistant to five classes of antibiotics, i.e. chloramphenicol, ampicillin, trimethoprim-sulfamethoxazole, fluoroquinolones, and third-generation cephalosporin. Although outbreaks of XDR S. typhi have been seen in different parts of Pakistan, its prevalence is rare in the Western world $[1,2]$.

Our patient had several unique features. Ileocecal thickening, as seen in our patient, could have been due to neoplastic, inflammatory, infectious or ischemic conditions but also be a normal variant [3]. In general, benign conditions result in bowel wall thickening of less than $2 \mathrm{~cm}$, whereas wall thickening greater than 3 cm usually indicates a neoplastic condition. However, entities that cause mild bowel wall thickening often overlap, and wall thickening may be marked in infectious or ischemic processes. Ileocecal thickening is a rare complication of typhoid infection as seen in our patient but it is well published in literature [4]. Mesenteric lymphadenopathy is more common in nontyphoidal salmonellosis [5].

Superficial skin abscesses are an unusual presentation of $S$. typhi septicemia, most notably occurring where there is an underlying predisposition, such as sickle cell anemia and in severely ill or immunocompromised patients [6-9]. In a series of 240 adult cases of typhoid fever, subcutaneous abscesses from which S. typhi was isolated, occurred in $2.9 \%$ of patients having an underlying predisposing condition [10]. Our patient is unique in that the large subcutaneous abscess occurred without any underlying risk factor.

Typhoidal hepatitis with transaminitis occurs in $21 \%-60 \%$ of cases of typhoid fever [11,12]. However, severe hepatic derangement simulating acute viral hepatitis is very rare. The presentation with elevation of transaminases, total bilirubin, gamma glutamate dehydrogenase (GGT) and deranged prothrombin time/ international normalized ratio (PT/INR) similar to that of severe acute viral hepatitis, as observed in this case, makes this case unique. Cases of acute viral hepatitis with typhoid have been reported by others [13$15]$.

Although mild gastrointestinal bleeding is common in enteric fever, massive, lower gastrointestinal bleeding is rare. The terminal ileum is the most commonly involved site, followed by the ileocecal valve, ascending colon, and transverse colon [16]. There are case reports of enteric fever presenting with massive gastrointestinal hemorrhage requiring $\mathrm{CT}$ angiography with a view towards embolization or endoscopic hemoclipping $[17,18]$.

Fever defervescence time in multidrug resistant (MDR) typhoid ranges from 3.9 to 5.7 days as reported by Jeeyani et al. [19]. A six-year retrospective survey from a tertiary care hospital in Singapore also found that the median value for time from initiation of appropriate antibiotic treatment to fever defervescence was five days [20]. There is no data available for time to fever defervescence in XDR Salmonella.

This case had several unusual features: XDR Salmonella typhi complicated by acute hepatitis, large soft tissue abscesses, DIC, CT scan evidence of thickened ileocecal junction with significant mesenteric lymphadenopathy, and massive lower GI bleeding that required invasive radiological intervention to stem the bleeding.

\section{Conclusions}

Typhoid fever usually manifests with prolonged fever, transaminitis, and GI symptoms. The clinician must, however, be aware of diverse manifestations that mimic other conditions. Diagnosis of complicated typhoid is clinched only through isolation of $S$. typhi in suspected clinical specimens. In this case we were able to isolate an extensively drug resistant $S$. typhi. Appropriate selection of antibiotics was made only after identification of the bacteria and the drug sensitivity.

\section{Additional Information}

\section{Disclosures}

Human subjects: Consent was obtained by all participants in this study. Conflicts of interest: In compliance with the ICMJE uniform disclosure form, all authors declare the following: Payment/services info: All authors have declared that no financial support was received from any organization for the submitted work. Financial relationships: All authors have declared that they have no financial 
relationships at present or within the previous three years with any organizations that might have an interest in the submitted work. Other relationships: All authors have declared that there are no other relationships or activities that could appear to have influenced the submitted work.

\section{Acknowledgements}

I would like to thank my wife for her support and encouragement during this difficult case report, and my supervisor Dr. Naseem Salahuddin.

\section{References}

1. Qamar FN, Yousafzai MT, Khalid M, et al.: Outbreak investigation of ceftriaxone-resistant Salmonella enterica serotype typhi and its risk factors among the general population in Hyderabad, Pakistan: a matched case control study. Lancet Infect Dis. 2018, 18:1368-76. 10.1016/S1473-3099(18)30483-3

2. Klemm EJ, Shakoor S, Page AJ, et al.: Emergence of an extensively drug-resistant Salmonella enterica serovar typhi clone harboring a promiscuous plasmid encoding resistance to fluoroquinolones and thirdgeneration cephalosporins. MBio. 2018, 9:20-9. 10.1128/mBio.00105-18

3. Macari M, Balthazar EJ: CT of bowel wall thickening: significance and pitfalls of interpretation . AJR Am J Roentgenol. 2001, 176:1105-16. 10.2214/ajr.176.5.1761105

4. Balthazar E, Charles HW, Megibow AJ: Salmonella and Shigella-induced ileitis: CT findings in four patients . J Comput Assist Tomogr. 1996, 20:375-378. 10.1097/00004728-199605000-00008

5. Ahmed N, Saeed Z, Tariq M: Abdominal lymphadenopathy: an atypical presentation of enteric fever . Asian Pac J Trop Biomed. 2012, 2:409-410. 10.1016/\$2221-1691(12)60066-5

6. Vellodi C: Subcutaneous Salmonella abscesses - an unusual manifestation of salmonellosis . J R Soc Med. 1990, 83:190.

7. Molina M, Ortega G, Pérez Garcia A, Pretel L: Cutaneous abscesses caused by Salmonella. [Article in Spanish]. Enferm Infecc Microbiol Clinic. 1990, 8:259-260.

8. Shamiss A, Thaler M, Nussinovitch N, Rosenthal T: Multiple Salmonella enteritidis leg abscesses in a patient with systemic lupus erythematosus. Postgrad Med J. 1990, 66:486-488. 10.1136/pgmj.66.776.486

9. Indrisano JP, Simon GL: Facial Salmonella abscess. Ann Intern Med. 1989, 110:171. 10.7326/0003-4819-1102-171_1

10. Carswell W, Magrath IT: Skin ulceration caused by Salmonella dublin . Br Med J. 1973, 1:331-332. 10.1136/bmj.1.5849.331

11. Khosla SN, Singh R, Singh GP, Trehan VK: The spectrum of hepatic injury in enteric fever . Am J Gastroenterol. 1988, 83:413-6.

12. Morgenstern R, Hayes PC: The liver in typhoid fever: always affected, not just a complication . Am J Gastroenterol. 1991, 86:1235-9.

13. Ramanathan M: Unusual hepatic manifestations in typhoid fever. Singapore Med J. 1991, 32:335-7.

14. El-Newihi HM, Alamy ME, Reynolds TB: Salmonella hepatitis: analysis of 27 cases and comparison with acute viral hepatitis. Hepatology. 1996, 24:516-9. 10.1002/hep.510240308

15. Balasubramanian S, Kaarthigeyan K, Srinivas S, Rajeswari R: Serum ALT: LDH ratio in typhoid fever and acute viral hepatitis. Indian Pediatr. 2010, 47:339-41.

16. Lee JH, Kim JJ, Jung JH, et al.: Colonoscopic manifestations of typhoid fever with lower gastrointestinal bleeding. Dig Liver Dis. 2004, 36:141-46. 10.1016/j.dld.2003.10.013

17. Mel SD, Wong RK: Massive gastrointestinal hemorrhage secondary to typhoid colitis: a case report and literature review. ScienceDirect. 2015, 2:83-85. 10.1016/j.idcr.2015.08.003

18. Wang H, Dong XL, Yu XM, Chung KS, Gao JP: Successful endoscopic hemoclipping of massive gastrointestinal bleeding from paratyphoid A fever. World J Gastroenterol. 2015, 21:1040-43. 10.3748/wig.v21.i3.1040

19. Jeeyani HN, Prajapati BS, Bloch A: Enteric fever in children: clinical profile, sensitivity patterns and response to antimicrobials. GCSMC J Med Sci. 2015, 4:40-43.

20. Hatib NAA, Chong CY, Thoon KC, Tee NWS, Krishnamoorthy SS, Tan NWH: Enteric fever in a tertiary pediatric hospital: a retrospective six-year review. Ann Acad Med Singapore. 2016, 45:297-302. 